\title{
Preschoolers' Use of Form Class Cues to Learn Descriptive Proper Names
}

\author{
D. Geoffrey Hall, Sandra R. Waxman, Serge Brédart, and Anne-Catherine Nicolay
}

\begin{abstract}
This study examined 3- and 4-year-old preschoolers' ability to learn proper names containing familiar descriptions. Children saw a novel creature with a familiar property (it was red) and heard either an adjective ("This is a red one") or a descriptive proper name ("This is Mr. Red"). The creature was then transformed, losing the property (e.g., it became green). Children had to extend the word to either the transformed original creature or a new creature bearing the original property (another red creature). Children, especially 4-year-olds, extended the adjective to the new creature but were significantly more likely to extend the proper name to the original creature. Lexical form class cues provided potent information about word meaning, directing preschoolers to reinterpret familiar descriptive terms (adjectives) as homophonic terms designating unique individuals (proper names).
\end{abstract}

Proper names typically originated as expressions that described individuals (e.g., Alford, 1987). In many cases, these descriptions can still be readily understood. For example, it is easy to grasp the original descriptive content of a number of English second names, which arose during the Middle Ages and accurately characterized individuals' occupations (e.g., Smith, Baker, Shepherd), places of habitation (e.g., Brooks, Hills, Fields), physical characteristics or disposition (e.g., Short, White, Moody, Blunt), or family relations (often through use of a patronym, e.g., Johnson for son of John, or Peters for son of Peter) (e.g., Bryson, 1990; Matthews, 1966; Wilson, 1998). It is usually more difficult to determine the original descriptive meaning connected to frequently occurring English given names, because they often first appeared centuries or millennia ago, making the associated descriptions familiar now only to etymologists. But a number of typical English

D. Geoffrey Hall, Department of Psychology, University of British Columbia; Sandra R. Waxman, Department of Psychology, Northwestern University; Serge Brédart and Anne-Catherine Nicolay, Cognitive Psychology Unit, University of Liège.

This research was supported by an operating grant from the Natural Sciences and Engineering Research Council (NSERC) of Canada to the first author, by National Institutes of Health Grant 28730 and the North Atlantic Treaty Organization (NATO) program for international research to the second author, and by a grant from Les Actions de Recherche Concertées (convention 99/04-246) from the French-speaking community of Belgium to the third author. We are grateful to Rachel Moser, Kelley Persoage, and Jodi Pawluski for their assistance with English data collection, and to Amy Booth for her assistance with a part of the data analysis. We thank two anonymous reviewers for extremely helpful comments on an earlier version of this manuscript.

Correspondence concerning this article should be addressed to D. Geoffrey Hall, Department of Psychology, University of British Columbia, 2136 West Mall, Vancouver, BC, V6T 1Z4, CANADA. Electronic mail may be sent to geoff@psych.ubc.ca. given names still have clear descriptive content, including several boys' names (e.g., Ernest, Victor), and a few girls' names describing desirable qualities (e.g., Bonnie, Faith), flowers (e.g., Lily, Rose), and jewels (e.g., Amber, Jewel) (Alford, 1987).

Even though conventional proper names in English often have an understandable descriptive meaning, any accuracy in the description today is likely coincidental. For example, it is almost certainly an accident if a man named Carpenter today is, in fact, a carpenter. Yet many proper names do remain intentionally descriptive of their bearers. For instance, in Iceland, second names are still true patronyms (e.g., a man named Leifur Halldorsson really is Leifur, the son of Halldor). And in many cultures, including our own, individuals often receive nicknames that are derived from faithful descriptions (e.g., Lefty as a name for a left-handed person, Curly as a name for a curly-haired person). Characters that appear in fiction, especially children's fiction, also frequently have proper names that contain truthful descriptions, from Snow White's dwarfs (e.g., the happy dwarf, Happy; the sleepy dwarf, Sleepy), to the farmer in the nowclassic children's show Captain Kangaroo (the green-clad Mr. Green Jeans), to the dog in the currently popular children's show Blue's Clues (the blue dog, Blue) (see Brédart \& Valentine, 1998). In a study of 60 cultures from around the world, Alford (1987) reported that more than two thirds had given names with evident meaning, most commonly descriptions of physical traits, personality or character traits, or places of birth or dwelling.

At first, it might appear that learning proper names derived from descriptive terms should pose

(C) 2003 by the Society for Research in Child Development, Inc. All rights reserved. 0009-3920/2003/7405-00019 
no special problems for children, especially when the description pertains to an individual's observable property or properties. For example, what could be easier than learning the name Bashful for a bashful dwarf? Yet proper names are not descriptive expressions. As many philosophers have argued, the logical role of proper names is not to describe individuals but rather to designate individuals uniquely, and to do so independently of their properties (e.g., Kripke, 1980). As a result, learning a proper name derived from a descriptive term logically requires reinterpreting a familiar describing expression as a designator. To do so, the child must be capable of extending such a word to a unique individual consistently across situations, regardless of the truth or falsity of the description. This requirement might make the mastery of these proper names particularly challenging for young children, especially where an individual changes over time in such a way that a once-true description becomes false. For example, suppose that Snow White's shy dwarf sought therapy and overcame his shyness. He would still be named Bashful even though he was no longer bashful in disposition.

Proper names derived from familiar descriptions are examples of cross-category homophones: words with two different meanings, each associated with a different lexical form class. For example, Bashful is a proper name that designates a particular individual; at the same time, it is an adjective that labels any individual who happens to be shy. There is clear evidence in the developmental literature that preschoolers' lexicons, like those of adults, contain homophones (e.g., bat/bat). Children understand that these expressions are associated with more than one meaning (e.g., flying mammal/baseball bat; Backscheider \& Gelman, 1995; see also Peters \& Zaidel, 1980), and they switch between the two meanings with some flexibility. For instance, children ranging in age from 3 to 6 years interpret a homophone appropriately when it is embedded in a rich and elaborate linguistic context that makes the proper meaning salient (e.g., Beveridge \& Marsh, 1991). Yet although previous research has documented children's adeptness in accessing existing homophones in their lexicons, little work has explored how children acquire homophones in the first place (but see Hall \& Moore, 1997). Moreover, no study has investigated children's ability to acquire cross-category homophones involving proper names derived from familiar adjectival descriptions.

One way that children might acquire proper names containing familiar descriptions is through lexical form class cues to word meaning. Several researchers have discovered that young children can use these cues to interpret novel proper names appropriately. For example, the findings from a number of studies indicate that children as young as 2 years understand that a novel word modeled as a proper name (e.g., "This is $X^{\prime \prime}$ ) designates an individual object (e.g., Gelman \& Taylor, 1984; Hall, 1991; Hall, Lee, \& Bélanger, 2001; Imai \& Haryu, 2001; Jaswal \& Markman, 2001; Katz, Baker, \& Macnamara, 1974; Liittschwager \& Markman, 1993; Macnamara, 1982; Sorrentino, 2001), but a novel word modeled as an adjective (e.g., "This is an X one $^{\prime \prime}$ ) provides a description of the object (e.g., Gelman \& Markman, 1985; Hall, Quantz, \& Persoage, 2000; Hall, Waxman, \& Hurwitz, 1993; Klibanoff \& Waxman, 2000; Landau, Smith, \& Jones, 1992; Smith, Jones, \& Landau, 1992; Taylor \& Gelman, 1988; Waxman, 1990, 1999; Waxman \& Booth, 2001; Waxman \& Markow, 1998). Because preschoolers can use form class cues to acquire purely arbitrary proper names (e.g., Dax), it is possible that they can also use these cues to learn proper names that are homophones of familiar descriptive terms. If preschoolers can use form class cues in this way, it would suggest that form class information is highly potent as a guide to word meaning, superseding the semantic information already associated with a word.

In four experiments, we investigated preschoolers' ability to use form class cues to acquire proper names that are homophones of familiar adjectives. In Experiment 1, we introduced English-speaking preschoolers to a character of a particular color, such as a novel red creature. We verified that our participants knew the meaning of the familiar English expression naming the color (e.g., red as a term to describe red things). For half the participants, we labeled the creature with this word modeled as an adjective, intending to describe a property of the object. We said, for example, that it was "a red one." For the other half, we labeled the same object with the same word, but we presented it in a sentence frame that indicated the word was to be treated as a proper name. For example, we said that it was "Mr. Red." Many languages, including English, have personal proper names derived from color words, words that often originally described an individual's skin or hair color (Matthews, 1966). We then told all participants a story involving a transformation of the creature, in which it lost its color (e.g., it became green). Finally, we introduced a second novel creature of a different kind, one that possessed the original color (e.g., a different red creature). 
To test whether preschoolers can use form class cues to reinterpret familiar adjectives as homophonic proper names, we examined children's extensions of the word. If preschoolers interpret familiar adjectives as labeling properties, they should have selected the unlabeled object with the familiar property (i.e., the red creature) after hearing an adjective. To the extent that they can use form class cues to reinterpret familiar descriptive terms as designating expressions, they should have been more likely to pick the originally labeled creature (i.e., the now-green creature) after hearing the proper name than after hearing the adjective. The form class cues indicating that the familiar descriptor was a proper name thus should have led children to set up a homophone in their lexicon, a designator. Experiments 2 through 4 were designed to gain further insight into preschoolers' understanding of descriptive proper names. They involved extending the work to include children acquiring a language other than English (Experiment 2) and to help clarify the results of Experiment 1 (Experiments 3 and 4).

\section{Experiment 1}

\section{Method}

Participants. There were 64 participants: thirtytwo 3-year-olds $(M=42$ months, $S D=3$ months $)$ and thirty-two 4-year-olds $(M=54$ months, $S D=5$ months). All had English as a first language. Within both age groups, 16 were assigned to the adjective condition and 16 to the proper name condition. There were roughly equal numbers of boys and girls in the two conditions at both ages. Three additional 3-year-olds were tested but excluded from the final sample for failing the posttest (see the following discussion). Children were recruited and tested individually in preschools in Greater Vancouver, British Columbia. They were from predominantly middle- and upper-middle-class backgrounds.

Stimuli. There were four sets of three black-andwhite line drawings of novel creatures, colored using coloring pencils and mounted on $3 \mathrm{in} . \times 5 \mathrm{in}$. cards. These were similar to those used in Hall and Moore (1997). Each set contained a target drawing and two test drawings. The target drawing depicted a novel creature of a particular color (e.g., a red novel creature). One test drawing was the individual match. It showed the same target creature in a different color (e.g., the target creature colored green). The other test drawing was the property match. It showed a novel creature of a different kind than the target but the same color (e.g., a novel

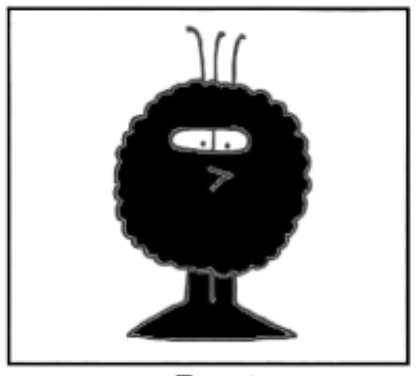

Target

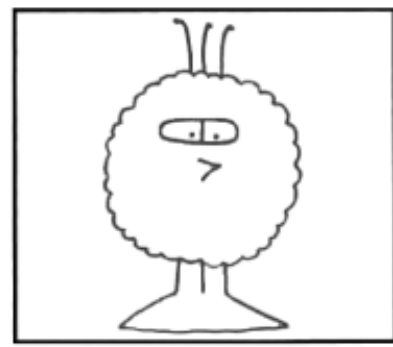

Individual Match

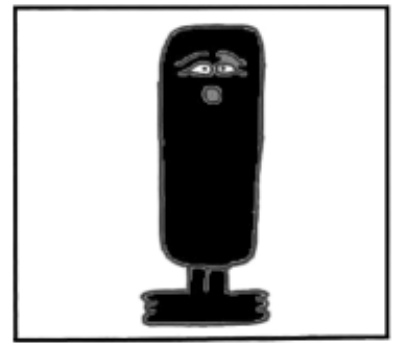

Property Match
Figure 1. Sample stimulus triad from Experiments 1, 1a, and 2. Black shading corresponds to red coloring; no shading corresponds to green.

creature of a different kind colored red). Figure 1 shows a sample triad. The target stimulus colors (and the contrasting colors) in the four sets were red (green), blue (red), green (brown), and brown (blue). We also used a puppet.

Procedure. The experimenter began the first trial (of four) by introducing children to a puppet. Children heard that the puppet now would go away and hide where he could not see or hear anything but would come back later to ask them for help. The experimenter brought out the first set of three drawings (see Figure 1) and placed the target drawing (a red novel creature) in front of the participant. The target was always labeled with a familiar term describing its color (red), but the word was presented in a different position within a noun phrase according to the condition. In the adjective condition, the term was modeled as an adjective. The experimenter said, "Look! Do you see this? This is a red one." In the proper name condition, it was modeled as a proper name. The experimenter said, "Look! Do you see this? This is Mr. Red." In both conditions, the experimenter repeated the label (i.e., "a red one" or "Mr. Red") and then asked children to repeat it.

In both conditions, the experimenter then pointed out three features of the target object. The experimenter said of the red novel creature, "He's got three points on his head, a round body, and pointy feet." 
This information was included to draw attention to the distinguishing physical traits of the target creature, so that children would differentiate it from the contrasting creature that was the property match. The three features we described for the three other target objects were as follows: for the blue target, "has five points on his head, a bubbly nose, and a square body"; for the green target, "has three points on his head, wide eyes, and three toes on his feet"; and for the brown target, "has a flat head, a pointy nose, and pointy feet."

The experimenter then said, "One day, the red one (Mr. Red) was out walking through the woods. And you know what? He fell into some yucky green stuff. So then he looked just like this." At this point, the experimenter removed the target drawing and brought out the first test drawing, the individual match (the target creature now colored green). The experimenter said, "Then he kept on walking until he met this one. Look here." At this point, the experimenter brought out the second test drawing, the property match (a novel creature of a different kind colored red). Half the time (in a balanced fashion), the property match was placed to the left of the individual match; half the time, it was placed on the right.

The experimenter continued, saying, "Now my puppet is going to come out from hiding to ask you a question. So listen carefully." The experimenter then brought back the puppet, who asked, "Can you show me the red one (Mr. Red)?" Children chose between the two test drawings by pointing, and the experimenter wrote down these choices. The puppet thanked the child. The same procedure was repeated on each of the four trials. The order of presentation of the four stimulus sets was counterbalanced across children.

After the fourth and final trials, we administered a brief posttest to verify that all children knew terms for all the colors used in the task. We showed participants patches of each of the colors in the same shades they had just seen and asked them to name them (i.e., "Can you tell me what color that is?"). All participants included in the final sample passed this posttest. Anyone who failed to name every color correctly was excluded from the final sample. The entire procedure lasted about $10 \mathrm{~min}$.

\section{Results and Discussion}

Our interest was in understanding children's ability to use form class cues to reinterpret familiar adjectives as proper names; therefore, we framed our hypotheses in terms of the tendency to select the individual match. Specifically, (a) if children knew the familiar adjectives, they should not have selected the individual match in the adjective condition, preferring instead the property match; and (b) if children could take advantage of form class cues to reinterpret the familiar adjectives as proper names, they should have been more likely to select the individual match in the proper name than in the adjective condition.

We found support for both hypotheses. We set an alpha level of .05 in statistical tests for all experiments. We report exact $p$ values, though we describe those lower than .0001 as $p<.0001$. We began by focusing on the mean proportions of individual match choices (see Table 1). Preschoolers clearly knew the familiar adjectives and were able to use these words in our transformation task. In the adjective condition, the mean proportion of individual match choices was significantly less than chance by $t$ test among both 3-year-olds, $t(15)=$ $31.00, p<.0001$, and 4-year-olds, $t(15)=31.00$, $p<.0001$, where chance was .50 for this two-option forced-choice task. Preschoolers also showed an ability to use form class cues to reinterpret the familiar adjectives as proper names. In the proper name condition, the mean proportion of individual match choices was higher than in the adjective condition: Among 3-year-olds, it was significantly less than chance, $t(15)=2.39, p=.03$, and among 4 year-olds, the proportion was statistically at chance.

Table 1

Mean Proportion (Standard Deviation) of Individual Match Choices

\begin{tabular}{lcl}
\hline & $\begin{array}{c}\text { Adjective } \\
\text { condition }\end{array}$ & $\begin{array}{c}\text { Proper name } \\
\text { condition }\end{array}$ \\
\hline Experiment 1 (English) & $0.02(0.06)^{* * *}$ & $0.27(0.39)^{*}$ \\
$\quad$ 3-year-olds & $0.02(0.06)^{* * *}$ & $0.59(0.41)$ \\
$\quad$ 4-year-olds & - & $0.85(0.27)^{* *}$ \\
Experiment 1a (English) & - & $0.90(0.21)^{* * *}$ \\
$\quad$ 3-year-olds & & \\
$\quad$ 4-year-olds & $0.05(0.17)^{* * *}$ & $0.35(0.35)$ \\
Experiment 2 (French) & $0.06(0.21)^{* * *}$ & $0.53(0.43)$ \\
$\quad$ 3-year-olds & $0.02(0.06)^{* * *}$ & $0.47(0.36)$ \\
$\quad$ 4-year-olds & $0.02(0.06)^{* * *}$ & $0.61(0.45)^{*}$ \\
Experiment 3 (English) & & \\
3-year-olds & $0.00(0.00)$ & $0.65(0.48)$ \\
$\quad$ 4-year-olds & & \\
Experiment 4 (English) & & \\
4-year-olds & &
\end{tabular}

Note. $N=16$ per condition in Experiments 1 and 3. $N=10$ per condition in Experiment 1a. $N=24$ per condition in Experiment 2. $N=12$ per condition in Experiment 4 .

${ }^{*} p<.05 .{ }^{* *} p<.001 .{ }^{* * *} p<.0001$. 
We submitted the mean proportions of individual match choices to a 2 (condition: proper name, adjective) $\times 2$ (age: 3-year-olds, 4-year-olds) between-subjects analysis of variance (ANOVA). There was a significant main effect of condition, $F(1$, $60)=27.27, p<.0001$, indicating more choices of the individual match in the proper name than in the adjective condition. There was also a main effect of age, $F(1,60)=4.28, p=.04$, revealing that 4 -year-olds were more likely than 3 -year-olds to select the individual match. The Condition $\times$ Age interaction was also significant, $F(1,60)=4.28, p=.04$, indicating that the condition effect was stronger for 4-yearolds than for 3-year-olds. However, simple effects tests on the effect of condition within each age group revealed a significant result for both 3-year-olds, $F(1$, $60)=4.95, p=.03$, and 4-year-olds, $F(1,60)=26.48$, $p<.0001$. We also uncovered a significant condition effect in both age groups when we reanalyzed the data with stimulus sets rather than participants as a random effect: for 3-year-olds, paired $t(3)=9.80$, $p=.002$, and for 4-year-olds, paired $t(3)=37.00$, $p<.0001$.

We then analyzed each child's pattern of selection of the individual match across the four trials. We classified any child who made 4 (out of 4 ) individual match choices an individual match chooser (see Table 2). The odds of being classified an individual match chooser by chance alone were .0625 because the probability of making four of four individual match choices was $.5 \times .5 \times .5 \times .5$. These data confirmed that preschoolers knew the familiar adjectives: In the adjective condition, no child in either

Table 2

Number of Individual Match Choosers (Number/Condition)

\begin{tabular}{lcc}
\hline & $\begin{array}{c}\text { Adjective } \\
\text { condition }\end{array}$ & $\begin{array}{c}\text { Proper name } \\
\text { condition }\end{array}$ \\
\hline Experiment 1 (English) & $0 / 16$ & $3 / 16$ \\
$\quad$ 3-year-olds & $0 / 16$ & $9 / 16^{*}$ \\
4-year-olds & - & $7 / 10^{*}$ \\
Experiment 1a (English) & - & $8 / 10^{*}$ \\
3-year-olds & & $3 / 24$ \\
4-year-olds & $0 / 24$ & $10 / 24^{*}$ \\
Experiment 2 (French) & $1 / 24$ & $3 / 16^{*}$ \\
3-year-olds & & $7 / 16^{*}$ \\
4-year-olds & $0 / 16$ & $7 / 12^{*}$ \\
Experiment 3 (English) & $0 / 16$ & \\
3-year-olds & & \\
4-year-olds & & \\
Experiment 4 (English) & & \\
4-year-olds & &
\end{tabular}

age group was an individual match chooser. The data also confirmed their ability to use form class cues to reinterpret the familiar adjectives as proper names: There were more individual match choosers in the proper name condition. Among 3-year-olds, there were three individual match choosers; among 4-year-olds, there were nine. This last number is significantly greater than would be expected by chance, according to the binomial theorem, $p<.05$. We then compared the number of individual match choosers in the two conditions at each age. Among 3year-olds, the difference between conditions was not significant. Among 4-year-olds, however, there were significantly more in the proper name condition than in the adjective condition, $\chi^{2}(1, N=32)=9.89$, $p=.002$, corrected for continuity.

In sum, preschoolers rarely selected the individual match in the adjective condition; as predicted, they preferred the property match. Also as predicted, children were more likely to choose the individual match in the proper name condition than in the adjective condition. Form class cues to word meaning thus were sufficiently powerful to drive preschoolers to establish cross-category homophones in their lexicons: to reinterpret familiar adjectives as proper names.

The results of Experiment 1 raise two questions. First, to what extent did the descriptiveness of the proper names pose a measurable problem for preschoolers? Previous findings indicate that children as young as 2 years map nondescriptive proper names to unique individuals (e.g., Hall et al., 2001; Sorrentino, 2001). Perhaps children's performance in Experiment 1 reflected their difficulty in tracking the target individual through our transformation task, and this procedural difficulty obscured their ability to use the form class cues that we provided. If this were the case, they should also have difficulty interpreting nondescriptive proper names in this transformation task. Second, what was the source of the change between 3- and 4-year-olds in their tendency to map a descriptive proper name to the target individual? Was it an increasing reliance on form class cues or simply an improving ability to trace the identity of objects through our transformation task?

To address these questions, we conducted Experiment 1a. This was a modified replication of the proper name condition of Experiment 1, using nondescriptive proper names (e.g., Mr. Smith). If the descriptiveness of the proper names really did create a difficulty for preschoolers, children should be more likely to interpret a proper name as referring to the target individual in Experiment 1a 
than in Experiment 1. And if the change between 3and 4-year-olds in Experiment 1 really did reflect an improved ability to exploit form class cues to reinterpret descriptive terms as designating expressions, 3- and 4-year-olds in Experiment 1a should be equally adept in interpreting these nondescriptive proper names.

\section{Experiment 1a}

\section{Method}

Participants. There were 20 participants: ten 3year-olds $(M=42$ months, $S D=4$ months $)$ and ten 4-year-olds $(M=53$ months, $S D=3$ months). All had English as a first language. There were roughly equal numbers of boys and girls in the two conditions at both ages. Children were recruited and tested as in Experiment 1; none had taken part in that experiment. They were from the same socioeconomic backgrounds as those in Experiment 1.

Stimuli. These were the same as in Experiment 1.

Procedure. This was the same as in the proper name condition of Experiment 1, with one exception. Instead of using descriptive proper names, we used nondescriptive proper names. These were: $\mathrm{Mr}$. Smith, Mr. Jones, Mr. Clark, and Mr. Moore.

\section{Results and Discussion}

Both 3- and 4-year-olds excelled at interpreting nondescriptive proper names accurately in our transformation task. We again began by focusing on the mean proportions of individual match choices in each age group (see Table 1). Both 3- and 4-yearolds interpreted the nondescriptive proper names as extending to the individual match. The mean proportion of individual match choices was significantly greater than chance by $t$ test among both 3year-olds, $t(15)=4.12, p=.0009$, and 4-year-olds, $t(15)=6.00, p<.0001$, where chance was .50 for this two-option forced-choice task. Moreover, there was no difference between age groups in their tendency to select the individual match.

As in Experiment 1, we then classified any child who made four (out of four) individual match choices an individual match chooser (see Table 2). Seven 3-year-olds and eight 4-year-olds received this classification. Both numbers are significantly greater than chance, according to the binomial theorem, $p<.05$. These results provide further evidence that both 3- and 4-year-old preschoolers excelled in interpreting nondescriptive proper names accurately as mapping to individuals.
In sum, the results of Experiment 1a indicate that the descriptiveness of the proper names in Experiment 1 did depress preschoolers' ability to interpret these expressions appropriately. Preschoolers were better at interpreting nondescriptive proper names (Experiment 1a) than descriptive proper names (Experiment 1). Thus, they clearly had no general difficulty in tracking the individual's identity through transformation in this task. Moreover, 3and 4-year-olds were equally adept at interpreting nondescriptive proper names appropriately, indicating that the demands of the task were well within the grasp of both age groups. This result suggests that the improvement between 3- and 4-year-olds in Experiment 1 did reflect an increase in children's ability to use form class cues to reinterpret the descriptive terms as designators.

In Experiment 2, we extended Experiment 1 to include speakers of a language other than English. The need to establish cross-category homophones is not a peculiarity for speakers of English. On the contrary, homophony involving adjectives (descriptive terms) and proper names (designating terms) arises across languages. Thus, it is important to broaden the generality of our findings by examining other language groups, ultimately including those in which proper names maintain some accurate description (e.g., those languages spoken in Scandinavia). In Experiment 2, we took the initial step of examining whether our findings generalize to another language like English, in which proper names are nondescriptive.

In France (and French-speaking parts of Belgium), as in England, second names typically began as expressions that faithfully described individuals (e.g., a man named Boulanger (Baker) was once, in fact, a baker; Wilson, 1998), and proper names may contain accurate descriptions even today. However, in France (and French-speaking Belgium), as in England, modern proper names are only accidentally descriptive. In Experiment 2, we thus examined French-speaking preschoolers' sensitivity to form class information when faced with the task of acquiring proper names containing descriptions. Our prediction was that these children would perform just like the English-speaking children in Experiment 1.

\section{Experiment 2}

\section{Method}

Participants. There were 96 participants: fortyeight 3-year-olds ( $M=43$ months, $S D=4$ months) 
and forty-eight 4-year-olds ( $M=57$ months, $S D=4$ months). All had French as a first language. Within both age groups, 24 were assigned to the adjective condition and 24 to the proper name condition. There were roughly equal numbers of boys and girls in the two conditions at both ages. Children were recruited and tested individually in schools in the area of Liège, Belgium. They were from a mix of socioeconomic backgrounds.

Stimuli. These were the same as in Experiment 1.

Procedure. This was the same as in Experiment 1, with three exceptions. First, we used a direct French translation of the script (see the Appendix). On each trial, the target was labeled with a familiar descriptive term (e.g., rouge) presented as an adjective in the adjective condition (e.g., " $\mathrm{C}$ 'est une chose rouge") and as a proper name in the proper name condition (e.g., "C'est Madame La Rouge"). Second, the androgynous target creatures were described as female (i.e., Madame). The reason for this change from Experiment 1 is that the form of the adjective (e.g., rouge) was always feminine in the adjective condition in order to agree in gender with the feminine noun, "chose". As a result, we also used the feminine form in the proper name condition. Third, in addition to pointing out three features of the target individual, we described three features of the property match when it was first introduced on each trial. We had omitted the description of the property match in Experiment 1. Comparisons of the performance of English speakers on the task with and without this description (Hall \& Moore, 1997) suggested that it does not affect the results.

\section{Results and Discussion}

The results closely replicated those from Experiment 1 , despite the fact that the children were now French speakers. We again began by focusing on the mean proportions of individual match choices (see Table 1). Preschoolers clearly knew the familiar adjectives. In the adjective condition, the proportion of individual match choices was significantly less than chance by $t$ test among both 3-year-olds, $t(23)=$ 13.34, $p<.0001$, and 4-year-olds, $t(23)=10.12$, $p<.0001$, where chance was .50. Preschoolers also showed an ability to use form class cues to reinterpret the familiar adjectives as proper names. In the proper name condition, the mean proportion of choices of the individual match was higher than in the adjective condition for both 3-year-olds and 4year-olds, but neither proportion differed statistically from chance.
We submitted the mean proportions of individual match choices to an ANOVA, as in Experiment 1. There was again a significant main effect of condition, $F(1,92)=37.24, p<.0001$, reflecting more choices of the individual match in the proper name condition than in the adjective condition. Planned simple effects tests on the effect of condition within each age group revealed that this effect held up for both 3-year-olds, $F(1,92)=11.41, p=.001$, and 4year-olds, $F(1,92)=27.47, p<.0001$. As in Experiment 1 , we also found a significant condition effect within each age group, by reanalyzing the data with stimulus sets rather than participants as a random effect: for 3-year-olds, paired $t(3)=7.25$, $p=.005$, and for 4-year-olds, paired $t(3)=45.00$, $p<.0001$.

We then analyzed each child's pattern of selection of the individual match across the four trials, as in Experiment 1 (see Table 2). These data confirmed that preschoolers knew the familiar adjectives: In the adjective condition, there were no individual match choosers among 3-year-olds and only one among 4year-olds. The data also confirmed that preschoolers had some ability to use form class cues to reinterpret the familiar adjectives as proper names: There were more individual match choosers in the proper name condition. Three 3-year-olds and ten 4-year-olds were individual match choosers. Only the number of 4-year-olds is significantly greater than would be expected by chance, according to the binomial theorem, $p<.05$. We then compared the number of individual match choosers in the two conditions at each age. Among 3-year-olds, the difference did not reach significance. Among 4-year-olds, however, there were more individual match choosers in the proper name condition than in the adjective condition, $\chi^{2}(1, N=48)=9.55, p=.002$.

In sum, the results of Experiment 2 closely replicated in French the English findings from Experiment 1. French-learning preschoolers did not choose the individual match in the adjective condition; as predicted, they preferred the property match. Consistent with our prediction, these preschoolers were also more likely to select the individual match in the proper name condition than in the adjective condition. Form class cues thus offered these French-speaking preschoolers potent information about word meaning, leading them to establish cross-category homophones in their lexicon. The findings provide a first step toward establishing the cross-linguistic and cross-cultural generality of our proposal.

In Experiments 1 and 2, we found a developmental progression from 3 to 4 years, a finding that 
suggests that 4-year-olds had a significantly stronger ability to use form class cues to reinterpret descriptive terms as homophonic proper names. The motivation for Experiment 3 was to replicate Experiment 1, with two procedural changes. First, we were concerned that participants in Experiment 1 might have chosen the transformed object not because it was the same individual but because they thought the change in color was temporary and therefore the object continued to have the original color underneath. To address this concern, we modified the description of the transformation in the story to specify that the change was permanent. Second, we wondered about the generality of children's ability to use form class cues to interpret adjectives in the adjective condition. In Experiment 1, we had always used the definite article (i.e., "Can you show me the $\mathrm{X}$ one?") to phrase our requests. To deal with this issue, we modified the grammatical cues so that they now involved the indefinite article (i.e., "Can you show me an X one?").

We made one additional change to the design of Experiment 1. Recall that the mean proportion of individual match choices among 4-year-olds in the proper name condition fell statistically at chance. In an effort to determine whether this chance proportion reflected random guessing caused by confusion about the task, or systematic responding, we added a third test drawing on each trial, showing a creature that looked similar to the identity and property matches, but that differed in both kind and property (color) from the target. Including this foil on each test trial lowered to .33 (from .50) the proportion of trials on which children should have chosen the individual match if they simply were selecting a creature at random. In making this change to our design, we followed a precedent set by Gelman and Taylor (1984) in their replication of Katz et al. (1974).

\section{Experiment 3}

\section{Method}

Participants. There were 64 participants: thirtytwo 3-year-olds ( $M=42$ months, $S D=4$ months) and thirty-two 4-year-olds $(M=53$ months, $S D=4$ months). All had English as a first language. Within each age group, 16 were assigned to the adjective condition and 16 to the proper name condition. For the children, there were roughly equal numbers of boys and girls in the two conditions at both ages. Three additional 3-year-olds were tested but excluded from the final sample, two for failing the posttest and one for failing to complete the task because of shyness. One additional 4-year-old was tested but excluded for failing the posttest. Participants were recruited and tested as in Experiment 1; none had taken part in any previous study. They were from the same socioeconomic backgrounds as those in Experiment 1.

Stimuli. These were the same as in Experiment 1, with one exception. Each set of drawings from Experiment 1 now included a fourth drawing, also colored using coloring pencils and mounted on a 3 in. $\times 5$ in. card. This was the foil. It showed a different kind of novel creature than either the individual match or the property match, and it was colored a different color from either of those drawings. For the red target, the foil was brown; for the blue target, it was green; for the green target, it was blue; and for the brown target, it was red.

Procedure. This was the same as in Experiment 1, with two primary procedural changes. First, we modified the description of the transformation in the story to specify that the change was permanent, in an attempt to make it less likely that participants would think that the object continued to have the original color underneath. The experimenter said that the yucky stuff into which the target fell "covered him all over and soaked him right through and could never ever come off." Second, we introduced the adjective in the adjective condition using the indefinite article (i.e., "Can you show me an X one?") rather than the definite article (i.e., "Can you show me the $X$ one?") to allow us to increase the generality of our results concerning preschoolers' use of form class cues to interpret adjectives.

In Experiment 3, we made one further procedural change. On each trial, the set of options included three drawings instead of two. These were the individual match, the property match, and the foil. As in Experiment 1, the experimenter introduced the individual match first. She then presented the property match and the foil in random order, stating that the individual match "kept on walking until he met this one (showing one of the two) and this one (showing the other)." These two were placed beside the individual match, to the right or left, in a balanced fashion.

\section{Results and Discussion}

The results closely replicated those from Experiment 1, despite our procedural modifications. We again began by examining the mean proportions of individual match choices (see Table 1). As in the 
previous experiments, preschoolers clearly knew the familiar adjectives. In the adjective condition, the proportion of individual match choices was significantly less than chance by $t$ test among both 3-yearolds, $t(15)=20.31, \quad p<.0001$, and 4-year-olds, $t(15)=20.31, p<.0001$, where chance was .33 for this three-option forced-choice task. Moreover, preschoolers were indeed sensitive to form class cues when interpreting the familiar adjectives modeled as proper names. In the proper name condition, the mean proportion of individual match choices was higher than in the adjective condition: Among 3year-olds, the proportion was statistically at chance, and among 4-year-olds, it was statistically greater than chance, $t(15)=2.47, p=.03$.

We submitted the mean proportions of individual match choices to an ANOVA, as in previous experiments. There was a significant main effect of condition, $F(1,60)=51.60, p<.0001$, reflecting more choices of the individual match in the proper name condition than in the adjective condition. Planned simple effects tests on the effect of condition within each age group revealed a significant result for both 3-year-olds, $F(1,60)=19.33, p<.0001$, and 4-year-olds, $\quad F(1,60)=33.18, p<.0001$. As in Experiment 1, we also found a significant condition effect within each age group, by reanalyzing the data with stimulus sets rather than participants as a random effect: for 3-year-olds, paired $t(3)=15.15$, $p=.0005$, and for 4-year-olds, paired $t(3)=32.91$, $p<.0001$.

We then analyzed each child's pattern of selection of the individual match across the four trials, as in previous experiments (see Table 2). Unlike previous experiments, the odds of being classified an individual match chooser by chance alone were .0123, because the probability of making four of four individual match choices was $.33 \times .33 \times .33 \times$ .33. These data again revealed that preschoolers knew the familiar adjectives: In the adjective condition, no child in either age group was an individual match chooser. The data also confirmed that preschoolers had the ability to use form class cues to reinterpret the familiar adjectives as proper names: There were more individual match choosers in the proper name condition. There were three individual match choosers among 3-year-olds and seven among 4-year-olds. Both numbers are significantly greater than chance, according to the binomial theorem, $p<.05$, although the number of 3-year-olds is small. We then compared the number of individual match choosers in the two conditions at each age. As in previous experiments, there was no significant difference among 3-year-olds. However, we found that there was a significant and predicted difference among 4-year-olds, $\chi^{2}(1, N=32)=6.58, p=.01$, corrected for continuity. ${ }^{1}$

In sum, the results of Experiment 3 closely replicated those of Experiment 1, despite our procedural changes. This fact offers evidence that children in the earlier experiment did not interpret the creatures' transformations as temporary and evidence that their ability to interpret adjectives generalizes to sentence frames involving either the definite or the indefinite article. We also replicated the results of Experiment 1, despite a change in the number of choices provided on each trial. Englishlearning preschoolers rarely chose the individual match or the foil in the adjective condition; instead, they preferred the property match. In addition, these preschoolers were more likely to select the individual match in the proper name condition than in the adjective condition. Form class cues thus again served as powerful guides to word meaning, directing preschoolers to set up cross-category homophones in their lexicons. Unlike Experiment 1, however, 4-year-olds' mean tendency to select the individual match in the proper name condition was statistically greater than chance. By the age of 4 years, children thus have a robust ability to use form class cues to reinterpret familiar adjectives as proper names. Our use of a two-item forced-choice task in Experiments 1 and 2 may have partly obscured this ability (cf. Gelman \& Taylor, 1984, in discussing their motivation for adding new objects to their test array in replicating Katz et al., 1974).

The results of the first three experiments provide evidence that preschoolers, especially 4-year-olds, have some understanding that descriptive proper names apply to individuals regardless of the truth or falsity of the description. In other words, they appreciate the arbitrariness of proper names. But there is another fundamental feature of the seman-

\footnotetext{
${ }^{1}$ In an effort to learn more about the consistency of children's performance in the proper name condition, we examined in greater detail their patterns of choices over the four trials in Experiments 1, 2, and 3. Recall that there were more individual match choosers among 4-year-olds than among 3-year-olds in all these experiments. In contrast, (a) there were more children who consistently chose the property match among 3-year-olds than among 4-year-olds in Experiments 1, 2, but not 3; and (b) there were more children who showed a mixed pattern of choices among 3-year-olds than among 4-year-olds in Experiments 1, 2, and 3 . Together these findings suggest that the increase between ages 3 and 4 in the number of individual match choosers reflected a tendency for children who consistently chose the property match or who showed a mixed pattern to become consistent in their selection of the individual match.
} 
tics of proper names: They pick out unique individuals. In our final experiment, we looked more closely at whether 4-year-olds appreciate this feature as well. Recall that in previous experiments (especially Experiment 3) only 4-year-olds showed a systematic understanding of the arbitrariness of descriptive proper names; as a result, we focused only on this age group in Experiment 4. The results of the previous experiments led us to suspect that 4year-olds appreciate that descriptive proper names map to unique individuals, because they picked the target individual following the loss of its original property rather than a different creature that had the original property. But it remains unclear why children picked the transformed original creature. It is possible that children selected the transformed original creature because it was that unique individual. But it is also possible that they chose it because it was an individual that had one or more perceptual properties in common with the pretransformation creature, such as a common shape and common physical features. This second possibility was left open because the property match creature matched the original creature in color but differed in other features. To rule out this possibility, we asked whether children would choose the transformed original creature over another creature that bore the labeled property and that looked identical to the original target. If children select the transformed original creature over a new creature that looked identical to the original target before its transformation, this would provide especially powerful evidence that preschoolers appreciate that descriptive proper names are arbitrary designators of individuals (cf. Hall et al., 2001; Sorrentino, 2001).

\section{Experiment 4}

\section{Method}

Participants. There were twenty-four 4-year-old participants $(M=53$ months, $S D=3$ months). All had English as a first language. Twelve each were assigned to the adjective condition and the proper name condition. There were roughly equal numbers of boys and girls in the two conditions. Children were recruited and tested as in Experiment 1; none had taken part in any previous study. They were from the same socioeconomic backgrounds as those in Experiment 1.

Stimuli. These were the same as in Experiment 1, but with one exception. The property match on each trial resembled the target drawing exactly, not merely in color. See Figure 2 for a sample triad.
Procedure. This was the same as in Experiment 1, but with three changes. First, instead of keeping the property match hidden until the transformed target creature met him in the woods, we introduced both creatures at the outset of the trial. We placed them about a foot apart on the experimenter's side of the table, facing children, and we told children that they looked exactly alike but hated to be mixed up. We made this change to avoid the possibility that children would become confused and think the property match was simply another drawing of the target creature. (This was not an issue in the previous experiments because the two looked very different.) Second, we kept the property match in the same place, clearly in view, throughout the trial to avoid confusion about its identity. When the transformed target creature met the property match in the woods, we carefully moved the property match forward to be alongside it. Third, we omitted the physical description of the target creature, because it now looked exactly like the property match.

\section{Results and Discussion}

The results closely replicated the results from 4year-olds in Experiment 1, despite the fact that the property match now looked identical to the target creature in all respects, not just in its color. We again began by examining the mean proportions of individual match choices (see Table 1). As in Experiment 1, 4-year-olds clearly knew the familiar adjectives. In the adjective condition, they never selected the individual match. Because this was a categorical finding, we did not compare it with chance. Preschoolers were again sensitive to form class cues when interpreting the familiar adjectives modeled as proper names. In the proper name condition, the mean proportion of individual match choices was higher than in the adjective condition but statistically at chance, as in Experiment 1.

We submitted the mean proportions of individual match choices to an ANOVA, as in Experiment 1. There was a significant main effect of condition, $F(1$, $22)=21.53, p=.0001$, reflecting more choices of the individual match in the proper name condition than in the adjective condition. As in Experiment 1, we also found a significant condition effect when we reanalyzed the data with stimulus sets rather than participants as a random effect, paired $t(3)=22.82$, $p=.0001$.

We then analyzed each child's pattern of selection of the individual match across the four trials, as in previous experiments (see Table 2). As in Experi- 


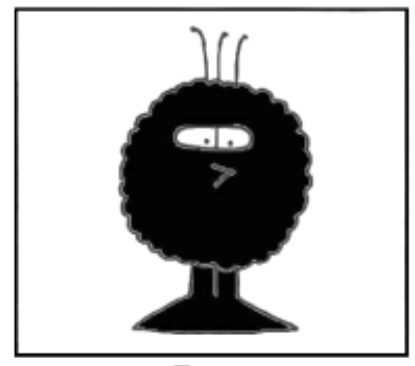

Target

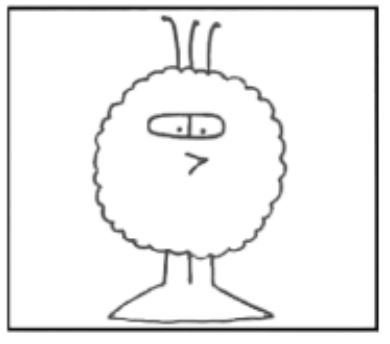

Individual Match

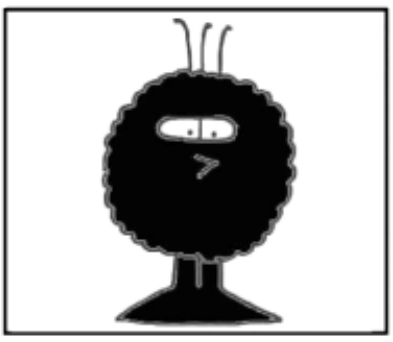

Property Match
Figure 2. Sample stimulus triad from Experiment 4. Black shading corresponds to red coloring; no shading corresponds to green.

ment 1, the odds of being classified an individual match chooser by chance alone were .0625 . These data again revealed that preschoolers knew the familiar adjectives: No child in the adjective condition was an individual match chooser. The data also confirmed that preschoolers had the ability to use form class cues to reinterpret the familiar adjectives as proper names: There were seven individual match choosers in the proper name condition. This number is significantly greater than chance, according to the binomial theorem, $p<.05$. We then compared the number of individual match choosers in the two conditions. As in Experiment 1, the difference was significant, $\chi^{2}(1, N=24)=7.26, p=.007$, corrected for continuity.

In sum, the results of Experiment 4 indicate that 4year-olds appreciate not only that descriptive proper names are arbitrary but also that these terms map to individuals: Children in the proper name condition selected the individual match over the property match when the property match looked exactly the same as the target creature. Form class cues again served as powerful guides to word meaning, directing 4-year-olds to reinterpret familiar descriptive terms (adjectives) as designating unique individuals (proper names).

\section{General Discussion}

Proper names are often derived from descriptions, yet their role is to designate not to describe individuals (e.g., Kripke, 1980). In four experiments, we explored English- and French-speaking preschoolers' ability to acquire proper names containing familiar descriptions. Children saw a novel creature that had a familiar property (e.g., it was red). Half heard it labeled with a familiar descriptive term presented as an adjective ("This is a red one"), and half heard it labeled with the same word modeled as a proper name ("This is Mr. Red"). The creature was then transformed so that it lost the property (it became green). Children were asked to extend the word either to the transformed creature or to a different creature bearing the familiar property (a different red creature). Children systematically extended the adjective to the new creature with the familiar property, but they were significantly more likely to extend the proper name to the transformed original creature. The effect was stronger among 4year-olds than among 3-year-olds. Lexical form class cues thus provided potent information about word meaning, leading preschoolers to acquire crosscategory homophones: to reinterpret familiar adjectives (describing individuals) as proper names (designating individuals).

Although previous research has explored children's understanding of existing homophones in their lexicon, little previous work has addressed the question of how children acquire homophones in the first place (Backscheider \& Gelman, 1995; see also Beveridge \& Marsh, 1991; Kohn \& Landau, 1990). The current findings offer evidence that form class cues are so powerful as guides to word meaning that they can foster word learning even when the to-belearned word is already familiar as a member of a different form class, and associated with a different type of meaning (see also Gelman \& Heyman, 1999; Hall \& Moore, 1997; Markman, 1989).

These results build on previous findings that suggest that children as young as 2 years can interpret conventional nondescriptive proper names (e.g., "This is Dax") as designating rather than describing individuals (e.g., Gelman \& Taylor, 1984; Hall, 1991; Hall et al., 2001; Imai \& Haryu, 2001; Jaswal \& Markman, 2001; Katz et al., 1974; Liittschwager \& Markman, 1993; Macnamara, 1982; Sorrentino, 2001). The current findings reveal that by 4 years of age, children's ability to interpret proper names appropriately has grown to encompass not only those that are purely conventional but also those that have some descriptive meaning. This marks the achievement of a firm grasp of both the linguistic and the logical distinction between description and designation. It indicates that preschoolers can (a) extend a descriptive label modeled as a 
proper name from one object to the same object after the description no longer applies and (b) resist extending this word to another object for which the description is clearly true.

We found a developmental progression between 3- and 4-year-olds in the ability to use form class cues to reinterpret familiar adjectives as proper names. Given that 2-year-olds are able to use form class cues to interpret nondescriptive proper names as designators (e.g., Hall et al., 2001; Sorrentino, 2001), we had an a priori reason to doubt that this progression reflected the initial emergence of an understanding that proper names are designators, or the first appearance of a sensitivity to the grammatical privileges of proper names. Indeed, the results of Experiment 1a revealed that both 3- and 4-yearolds were highly adept at learning nondescriptive proper names (e.g., Mr. Smith) in our transformation task. The developmental change thus appears to reflect a growth in children's willingness to treat form class cues as reliable guides to the interpretation of words, in the face of conflicting semantic information (i.e., the meaning already associated with the term). A number of studies have noted that during the preschool years, children come to rely more heavily on form class cues to guide their interpretations of new words, even when these cues conflict with other sources of information (e.g., Gelman \& Markman, 1985; Hall et al., 1993; Smith et al., 1992; Soja, 1992). A growing reliance on form class cues to interpret words could explain the appearance in our experiments at age 4 of a more stable ability to interpret descriptive proper names as designating individuals. This increasing reliance could also explain why even our 4-year-olds were not at ceiling in their tendency to treat the descriptive proper names as designating expressions.

The results of Experiments 1, 2, and 3 establish that preschoolers, especially 4-year-olds, prefer to map a descriptive proper name to a creature that lacks the labeled property than to a different-looking creature that bears the labeled property. The findings from Experiment 4 indicate that 4-year-olds show this preference even when the creature that bears the labeled property looks exactly like the originally labeled creature. These discoveries provide strong evidence that preschoolers understand not only that descriptive proper names are arbitrary (i.e., they do not necessarily map to a creature that bears the labeled property) but also that they trace the identity of individuals (i.e., they do not map to a different creature that looks identical to the originally labeled creature).
Throughout this article, we have argued that preschoolers' tendency to select the property match in the proper name condition reflects the miscategorization of a descriptive proper name as a descriptive term - an adjective. For example, we have proposed that they choose the property match as a referent for Mr. Blue because it is blue. But there is another possibility. Perhaps children who select the property match in the proper name condition do interpret the word as a designating term, but they also believe that the designated individual should possess any property entailed by the name. For instance, perhaps they choose the property match as a referent for Mr. Blue because it is that individual, but they also think that any individual with that designation should be blue. On both accounts, children's choice of the property match in the proper name condition reflects an inaccurate interpretation of a descriptive proper name as having a descriptive component. Yet because the two possibilities reflect different underlying ways of understanding these expressions, further research will be required to determine the precise basis for young children's misinterpretation.

The cross-linguistic replication of our results suggests that young children's ability to reinterpret descriptive terms as designating expressions is not specific to a particular language. This result marks an initial move toward establishing the crosslinguistic generality of our proposal. Of course, in the countries in which we conducted this work, conventional proper names (both given and second) are descriptive generally only by accident, though many other names are intentionally descriptive (e.g., nicknames, fictional characters' names). In future work, it will be important to investigate the interpretation of descriptive proper names by children in countries in which these expressions remain conventionally descriptive. In countries such as Iceland, second names still systematically provide some faithful description. Would young children raised in such places find it more difficult to interpret proper names as arbitrary designators of individuals? For example, would Icelandic children find it difficult to interpret Leifur Halldorrsson as applying to someone who turned out not to be the son of Halldor? If proper names are understood universally in a consistent way, children should ultimately come to understand descriptive proper names appropriately, regardless of their language or culture. However, it remains an open question whether the path to this understanding is mediated by children's experience in a particular linguistic or cultural community. 


\section{References}

Alford, R. (1987). Naming and identity: A cross-cultural study of personal naming practices. New Haven, CT: Human Relations Area Files (HRAF) Press.

Backscheider, A., \& Gelman, S. (1995). Children's understanding of homonyms. Journal of Child Language, 22, $107-127$.

Beveridge, M., \& Marsh, L. (1991). The influence of linguistic context on young children's understanding of homophonic words. Journal of Child Language, 18, $459-467$.

Brédart, S., \& Valentine, T. (1998). Descriptiveness and proper names retrieval. Memory, 6, 199-206.

Bryson, B. (1990). The mother tongue: English and how it got that way. New York: Avon.

Gelman, S. A., \& Heyman, G. D. (1999). Carrot-eaters and creature-believers: The effects of lexicalization on children's inferences about social categories. Psychological Science, 10, 489-493.

Gelman, S. A., \& Markman, E. (1985). Implicit contrast in adjectives versus nouns: Implications for word learning in preschoolers. Journal of Child Language, 12, 125-143.

Gelman, S. A., \& Taylor, M. (1984). How two-year-old children interpret proper and common names for unfamiliar objects. Child Development, 55, 1535-1540.

Hall, D. G. (1991). Acquiring proper names for familiar and unfamiliar animate objects: Two-year-olds' word learning biases. Child Development, 62, 1442-1454.

Hall, D. G., \& Moore, C. E. (1997). Red bluebirds and black greenflies: Preschoolers' understanding of the semantics of adjectives and count nouns. Journal of Experimental Child Psychology, 67, 236-267.

Hall, D. G., Lee, S. C., \& Bélanger, J. (2001). Young children's use of syntactic cues to learn proper names and count nouns. Developmental Psychology, 37, $298-307$.

Hall, D. G., Quantz, D., \& Persoage, K. (2000). Preschoolers' use of form class cues in word learning. Developmental Psychology, 36, 449-462.

Hall, D. G., Waxman, S. R., \& Hurwitz, W. (1993). How 2and 4-year-old children interpret adjectives and count nouns. Child Development, 64, 1651-1664.

Imai, M., \& Haryu, E. (2001). Learning proper nouns and common nouns without clues from syntax. Child Development, 72, 787-802.

Jaswal, V., \& Markman, E. (2001). Learning proper and common names in inferential versus ostensive contexts. Child Development, 72, 768-786.

Katz, N., Baker, E., \& Macnamara, J. (1974). What's in a name? A study of how children learn common and proper names. Child Development, 45, 469-473.

Klibanoff, R., \& Waxman, S. (2000). Basic-level object categories support the acquisition of novel adjectives: Evidence from preschool-aged children. Child Development, 64, 649-659.

Kohn, A., \& Landau, B. (1990). A partial solution to the homonym problem: Linguistic forms as an aid to learning. Developmental Psychology, 26, 204-211.
Kripke, S. (1980). Naming and necessity. Oxford, England: Blackwell.

Landau, B., Smith, L., \& Jones, S. (1992). Syntactic context and the shape bias in children's and adults' lexical learning. Journal of Memory and Language, 31, $807-825$.

Liittschwager, J., \& Markman, E. (1993). Young children's acquisition of proper versus common nouns. Poster presented at the biennial meetings of the Society for Research in Child Development, April, New Orleans, LA.

Macnamara, J. (1982). Names for things. Cambridge, MA: MIT Press.

Markman, E. (1989). Categorization and naming in children. Cambridge, MA: MIT Press.

Matthews, C. M. (1966). English surnames. London: Weidenfeld \& Nicolson.

Peters, A., \& Zaidel, E. (1980). The acquisition of homonymy. Cognition, 8, 187-207.

Smith, L., Jones, S., \& Landau, B. (1992). Count nouns, adjectives, and perceptual properties in children's novel word interpretations. Developmental Psychology, 28, $273-286$.

Soja, N. (1992). Inferences about the meanings of nouns: The relationship between perception and syntax. Cognitive Development, 7, 29-45.

Sorrentino, C. (2001). Individuation, identity, and proper names in cognitive development. Developmental Science, 4, 399-407.

Taylor, M., \& Gelman S. A. (1988). Adjectives and nouns: Children's strategies for learning new words. Child Development, 59, 411-419.

Waxman, S. R. (1990). Linguistic biases and the establishment of conceptual hierarchies: Evidence from preschool children. Cognitive Development, 5, 123-150.

Waxman, S. R. (1999). Specifying the scope of 13-montholds' expectations for novel words. Cognition, 70, B35B50.

Waxman, S. R., \& Booth, A. E. (2001). Seeing pink elephants: Fourteen-month-olds' interpretations of novel nouns and adjectives. Cognitive Psychology, 43, 217-242.

Waxman, S. R., \& Markow, D. B. (1998). Object properties and object kind: Twenty-one-month-old infants' extensions of novel adjectives. Child Development, 69, $1313-1329$.

Wilson, S. (1998). The means of naming. London: University College, London (UCL) Press.

\section{Appendix}

The key parts of the French script used in Experiment 2 are presented here.

\section{Introduction}

Adjective condition: "Regarde. Tu vois ceci? C'est une chose rouge (bleue, verte, brune). Elle a _.." 
Proper name condition: "Regarde. Tu vois ceci? C'est Madame La Rouge (La Bleue, La Verte, La Brune). Elle a —.."

\section{Description of Features of Target}

Red ("des antennes sur la tête," "un corps rond," "des pieds pointus"); blue ("des pointes sur la tête," "un nez en trompette," "un corps carré"); green ("des pointes sur la tête," "de larges yeux," "trois doigts de pied"); brown ("une tête plate," "un nez pointu," "des pieds pointus").

\section{Story}

“Un jour, la chose rouge (bleue...)/Madame La Rouge (La Bleue...) se promène dans les bois. Et tu sais quoi? Elle tombe dans une flaque de boue verte (rouge, brune, bleue). Elle ressemble alors à celle-ci.
Puis elle se remet en marche jusqu'à ce qu'elle rencontre celle-ci. Regarde ici. Elle a —_."

Description of Features of Property Match

For red target ("un grand corps," "une tête plate," "trois doigts de pied"); for blue target ("des pointes partout sur le corps," "un nez rond," "un grand corps"); for green target ("des antennes sur la tête," "de grands yeux," "un doigt de pied"); for brown target ("des antennes sur la tête," "un nez rond," "des pieds ronds").

Test Question

"Maintenant ma marionnette va sortir de sa cachette pour te poser une question. Ecoute bien. Peux-tu me montrer la chose rouge (bleue...)/ Madame La Rouge (La Bleue...)?" 